\title{
A Thermal Analysis Study on Blended Ternary Cement Paste
}

\author{
R. Nithya \\ Department of Physics, Annamalai University \\ Annamalainagar 608 002, Tamilnadu, India \\ E-mail: nivelan_15@yahoo.com \\ S.Barathan (Corresponding author) \\ Department of Physics, Annamalai University \\ Annamalainagar 608 002, Tamilnadu, India \\ E-mail: sbarathan.au@rediffmail.com \\ D.Govindarajan \\ Department of Physics, Annamalai University \\ Annamalainagar 608 002, Tamilnadu, India \\ E-mail:degerajan@rediffmail.com \\ K.Raghu \\ Department of Physics, Annamalai University \\ Annamalainagar 608 002, Tamilnadu, India \\ E-mail: raghuk_phy@rediffmail.com \\ N.Anandhan \\ Department of Physics, SRM University \\ Chennai, 603 203, Tamilnadu, India \\ E-mail: anandhan_kn@rediffmail.com
}

\begin{abstract}
Pastes containing High Alumina Cement (HAC) and Ordinary Portland Cement (OPC) were prepared using Ground Water (GW) and 5, 10, 15 and $20 \% \mathrm{SF}$. The setting time and compressive strength of these admixtured cement pastes were measured. The hydrated HAC blends were subjected to DTA/TG and DSC analysis. The recorded spectra were compared with the observed mechanical measurements of these blends. The hydration kinetics is well explained through these results. It is evidenced that $10 \% \mathrm{SF}$ addition is optimum for this blend.
\end{abstract}

Keywords: OPC, HAC, Admixture, TG/DTA

\section{Introduction}

High Alumina Cement (HAC) is one type among the non-Portland or Special cement. An increase in usage of HAC is extensively observed in recent past combining it with other binder systems even for day today application. An Ordinary Portland cement (OPC) and one or some mineral/chemical admixture usually serves as a mixer binder.

The replacement of HAC by OPC may develop a low strength. The substitution of admixture in this mix may develop a compressive strength higher than or equal to that of HAC under normal circumstances. Silicafume (SF) is preferred because it is highly pozzolanic due to its particle nature and improve the properties of paste/concrete in fresh as well as 
hardened state. Generally the addition of SF increases the strength and improves the resistance to sulfate attack. (Ramachandran et al., 2002)

Advanced materials research has recently focused on ettringite rich products (Brooks et al., 1990). One use of HAC is as a precursor to the formation of ettringite $\left(\mathrm{Ca}_{6} \mathrm{Al}_{2}\left(\mathrm{SO}_{4}\right)_{3}(\mathrm{OH})_{12 .} 6 \mathrm{H}_{2} \mathrm{O}\right)$. Blending HAC with anhydrite or gypsum is required for ettringite development. (Lamberet etal., 2005)

In the present investigation it has been planned to mix HAC, OPC and SF in different concentrations. A particular permutation and combination of this blend is expected to bring a maximum strength development, which can be identified by its mechanical properties. The hydration processes can be identified and explained using any analytical tool. In the present study as heat energy plays a vital role, it has been planned to explain the hydration process through TG/DTA, DSC and compare it with the mechanical studies.

\section{Experimental techniques}

The materials used in this work were Ordinary Portland Cement (OPC), High Alumina Cement (HAC) and SilicaFume (SF) supplied by Coromondal Ltd, Chennai, Ace Refractory, Chennai and Polygon Chemicals Ltd, Mumbai respectively. The chemical composition of the materials is given in table1.

Blended cement mix was initially prepared with $85 \% \mathrm{HAC}+10 \% \mathrm{OPC}+5 \% \mathrm{SF}$ and well mixed with the help of a mini vibrator. Then HAC was Substituted by 10, 15 and 20\% SF. Ground Water (GW) was used as medium. The water analysis is given in table 2 . The admixtured cement pastes were prepared in a water/cement ratio of 0.4 . The Initial and Final setting time of the blends were measured using the Vicat's apparatus (Fig.1). Their compressive strengths were also measured using a Techno Scient Trading Corporation machine (Fig.2). These procedure were well explained by Shetty (2004) and Sokkary et al.,(2004). The samples were hydrated to 1day, 3days, 1week and 4weeks. Proper curing was done for samples hydrated to more than one day. After dehydration as per the standard procedure (Moises Frías et al., 2002), the samples were powdered and analyzed using thermal analysis technique (TG/DTA, DSC). The TG/DTA and DSC were recorded from room temperature to $1000^{\circ} \mathrm{C}$ at a heating rate $10^{\circ} \mathrm{C} / \mathrm{min}$. The facilities available at CECRI, Karaikudi, Tamilnadu, India is made use of. For the sake of convenience HAC-control, $90 \% \mathrm{HAC}+10 \% \mathrm{OPC}$, $80 \% \mathrm{HAC}+10 \% \mathrm{OPC}+10 \% \mathrm{SF}$ and $70 \% \mathrm{HAC}+10 \% \mathrm{OPC}+20 \% \mathrm{SF}$ thermograms at 28 th day are shown in fig $3,4,5 \& 6$.

\section{Results and discussion}

DTA endothermic peak seen at around $130^{\circ} \mathrm{C}, 200^{\circ} \mathrm{C}, 275^{\circ} \mathrm{C}$ and $300^{\circ} \mathrm{C}$ may be assigned to $\mathrm{CAH}_{10}, \mathrm{C}_{3} \mathrm{AH}_{6}, \mathrm{C}_{2} \mathrm{AH}_{8}$ and $\mathrm{AH}_{3}$ respectively (Bradbury et al., 1976).

Hydrated HAC (one day) spectra show an endothermic peak at around $130^{\circ} \mathrm{C}$ the decomposition of $\mathrm{CAH}_{10}$ may be responsible for this.

In our present work a delayed set compared to other mixtures is observed. According to (Watson et al., 1990) the processess of setting and of nucleation and growth of the first hydrate are intimately linked. For a retarded set the nucleation is lower than at higher or lower temperatures. The significance is that the temperature range coincides with that at which formation of $\mathrm{CAH}_{10}$ becomes less favorable thermodynamically.

The formation of $\mathrm{C}_{2} \mathrm{AH}_{8}$ is sluggish and $\mathrm{C}_{3} \mathrm{AH}_{6}$ could be formed via conversion of one of the hexagonal hydrates. The present results are in accordance with this hypothesis and the retarding set is associated with the difficult nucleation of $\mathrm{CAH}_{10}$ and $\mathrm{C}_{2} \mathrm{AH}_{8}$ producing a longer dormant period. An endothermic peak is seen around $275^{\circ} \mathrm{C}$. The phase formation may be due to the decomposition of $\mathrm{CAH}_{10}$. The phase formation $\left(\mathrm{C}_{3} \mathrm{AH}_{6}\right)$ can be identified by the following reaction (Ana Hidalgo, et al.,2009).

$$
\begin{aligned}
& 3 \mathrm{CAH}_{10} \rightarrow \mathrm{C}_{3} \mathrm{AH}_{6}+2 \mathrm{AH}_{3}+18 \mathrm{H} \rightarrow(1) \\
& 3 \mathrm{C}_{2} \mathrm{AH}_{8} \rightarrow \mathrm{C}_{3} \mathrm{AH}_{6}+\mathrm{AH}_{3}+9 \mathrm{H} \rightarrow(2)
\end{aligned}
$$

These dehydration mechanisms are accompanied by micro cracking and porosity formation. This explains the decrease in compressive strength at $28^{\text {th }}$ day. (Chotard et al., 2005)

In fig (4) due to the replacement of HAC by OPC, the setting time is accelerated as compared to that of control. In any cement binary the sulfates and aluminates composition plays an important role in formation of ettringite (Sivakumar $e t$ al., 2008). Since the availability of sulfate in HAC is less, the formation of ettringite observes to be with lesser strength. This deficiency can be compensated by the addition of Silica fume (Ping Gu et al., 1997)

The Differential Thermal Analysis (DTA) thermogram of the composite with 5\%SF shows an endothermic peak centered at around $200^{\circ} \mathrm{C}$ due to $\mathrm{C}_{2} \mathrm{AH}_{8}$. It is observed that the additions of $\mathrm{SF}$ accelerate the setting time and increase the compressive strength at $28^{\text {th }}$ day. This may be attributed to the formation of calcium silicate hydrate which gives higher strength than the hydrate of calcium aluminate and sulphoaluminate.

An addition of $10 \% \mathrm{SF}$ to the composite shows an endothermic peak at around $200^{\circ} \mathrm{C}$ and $230^{\circ} \mathrm{C}$ which may be due to the formation of $\mathrm{C}_{2} \mathrm{AH}_{8}$ and $\mathrm{C}_{2} \mathrm{ASH}_{8}$ respectively. An increase in strength at $28^{\text {th }}$ day is due to this formation of 
stratlingite instead of $\mathrm{C}_{3} \mathrm{AH}_{6}$ and the formation of $\mathrm{CSH}$ (Midgley etal., 1978). The formation of this phase can be quoted by the following equation (Mohamed Heikal etal., 2004)

$\mathrm{C}_{2} \mathrm{AH}_{8}+2 \mathrm{CSH}+\mathrm{AH}_{3}+3 \mathrm{H} \rightarrow \mathrm{C}_{2} \mathrm{ASH}_{8} \rightarrow(3)$

An addition of $15 \% \mathrm{SF}$ composite shows a decreasing endothermic peak centered at around $300^{\circ} \mathrm{C}$. As the time increases it is could be noted that the formation of $\mathrm{C}_{2} \mathrm{ASH}_{8}$ decreases and $\mathrm{C}_{3} \mathrm{AH}_{6}$ became dominant at the $28^{\text {th }}$ day. Hence there is an accelerated setting time with lower compressive strength compared to that of $5 \%$ and $10 \% \mathrm{SF}$. According to (Ding et al., 1995) higher amount of SF keeps the non reacted SF particles as residual on the surface of products which may be responsible for lower strength.

Similar results were observed from the thermograms of composite $70 \% \mathrm{HAC}+10 \% \mathrm{OPC}+20 \% \mathrm{SF}$. The decreases in compressive strength with an addition of 15 and $20 \% \mathrm{SF}$ are less significant than that of the control cement paste. This may also be contributed to lesser $\mathrm{Ca}(\mathrm{OH})_{2}$ content found in blended cement pastes because of pozzolanic reaction consuming free lime disposable of $\mathrm{Ca}(\mathrm{OH})_{2}$ formation (Mohamed Heikal., 2006)

The Differential Scanning Calorimetry (DSC) thermograms shows only two endothermic peak located at around $275^{\circ} \mathrm{C}$ and $562^{\circ} \mathrm{C}$ with an enthalpy of $358.3 \mathrm{~J} / \mathrm{g}$ and $40.23 \mathrm{~J} / \mathrm{g}$. For the replacement of $10 \% \mathrm{OPC}$ shows the peak being shifted and gives an enthalpy of $102 \mathrm{~J} / \mathrm{g}$, lower than the control. For the addition of $5 \%, 10 \%, 15 \%$ and $20 \% \mathrm{SF}$ the enthalpy values are $139,157,152$ and $120 \mathrm{~J} / \mathrm{g}$ respectively. An increase in enthalpy value is due to the pozzolanic reaction of SF with the liberated $\mathrm{Ca}(\mathrm{OH})_{2}$ to produce $\mathrm{C}_{2} \mathrm{AH}_{8}$ and $\mathrm{C}_{4} \mathrm{AH}_{13}$ and then react with $\mathrm{CSH}$ to form $\mathrm{C}_{2} \mathrm{ASH}_{8}$ (Morsy et al.,2007). On the other hand the enthalpy decreases with an increase in SF content.

The Thermogravimetric Analysis (TG) is commonly used with DTA to follow the hydration reactions. From the TG curve the variations in weight loss with the temperature of properly cured cement pastes at $28^{\text {th }}$ day are shown in fig 3,4 , 5, and 6. The physically sorbed water at $110-120^{\circ} \mathrm{C}$, the peaks at 200 and $400^{\circ} \mathrm{C}$ are due to the dehydration of C-S-H and C-A-H hydrates. The mass is increased between 500 and $600^{\circ} \mathrm{C}$ because of the carbonation of $\mathrm{Ca}(\mathrm{OH})_{2}$. The result of TG/DTA and DSC serves as a complement in each other and compared with mechanical observations. Addition of 5 and $10 \% \mathrm{SF}$ shows an increase in the mass loss than the other mixes of 15 and $20 \% \mathrm{SF}$. This may be due to the principal reaction between SF and Calcium hydroxide from cement additional, cementititous aluminium containing C-S-H gel, together with crystalline products which include calcium aluminate hydrates and alumino silicate hydrates (ie $\mathrm{C}_{2} \mathrm{ASH}_{8}$, $\mathrm{C}_{4} \mathrm{AH}_{13}$ and $\mathrm{C}_{3} \mathrm{AH}_{6}$ ) (Heikal et al., 2005).

From the earlier discussion in the presence of SF, OPC in the hydration of HAC results in the formation of stratlingite compound. The formations of these hydrated phases remove $\mathrm{Ca}^{2+}$ ions from the pore solution and hence restrict the conversion of $\mathrm{CAH}_{10}$ and $\mathrm{C}_{2} \mathrm{AH}_{8}$ to the stable cubic hydrate $\mathrm{C}_{3} \mathrm{AH}_{6}$ i.e suppressing the extent of the conversion reaction. This is reflected by the strength development of $10 \% \mathrm{SF}$.

\section{Conclusions}

From the above findings it can be concluded that

- The addition of Silicafume increases the strength and decreases the setting time (i.e) it accelerates the reaction.

- The $10 \% \mathrm{SF}$ addition is supposed to be moderate as the strength increases uniformly. This is also supported by the DTA/TG and DSC study.

- $\quad$ The incorporation of SF in these systems contributes to the reduction of waste materials and therefore to a better sustainability development.

- $\quad$ The addition of SF reduces the cost to a suitable extent.

\section{References}

Ana Hidalgo, J., Garcia, L., Cruz Alonso, M., Fernandez, L. \& Carmen Andrade. (2009). Microstructure development in mixes of calcium aluminate cement with silica fume or fly ash. Journal of Thermal Analysis and Calorimetry, 49(2), $1-10$.

Brooks, SA, Sharp JH. (1990). Calcium Aluminate Cements, ettringite - based cements. In: Manghabhai RJ, editor. London: E \& F.Spon, ISBN 041945200 8(HB); P.335-349.

Bradbury, C., Callaway, P.M., \& Double, D.D. (1976). The conversion of High Alumina Cement/Concrete. Material Science and Engineering, 23, 43-53.

Bushnell-watson, S.M., \& Sharp, J.H. (1990). On the cause of the anomalous setting behaviour with respect to temperature of Calcium Aluminate Cements. Cement and Concrete Research, 20, 677-686.

Chotard, T., Rotureau, D., \& A. Smith, A. (2005). Analysis of acoustic emission signature during aluminous cement setting to characterise the mechanical behaviour of the hard material. Journal of the European Ceramic Society 25(6), $3523-3531$. 
El Sokkary, T.M., Assal, H.H., Kandeel, A.M. (2004). Effect of silica fume or granulated slag on sulphate attack of ordinary Portland and alumina cement blend. Ceramica International, 30, 133-138.

Ramachandran, Paroli, Beaudoin, Delgado. Handbook of Thermal Analysis of Construction Materials, 176.

Heikal, M., Morsy M.S., \& Radwan, M.M. (2005). Electrical Conductivity and Phase Composition of Calcium Aluminate Cement containing air-cooled and water-cooled slag at 20, 40 and $60^{\circ} \mathrm{C}$. Cement and Concrete Research, 35, 1438-1446.

Jian Ding, Yan Fu, J.J. Beaudoin. (1995). Stratlingite formation in HAC-SF systems: Significance Sodium Ions. Cement and Concrete Research 25(6), 1311-1319.

Lamberet S. (2005). Durability of ternary binders based on Portland cement, Calcium Aluminate Cement and Calcium Sulphate. These no.3151, Ecole Polytechnique Federale de Lasanne (EPFL) Switzerland.

Moises Frías and Joseph Cabrera. (2002). The effect of temperature on the hydration rate and stability of the hydration phases of Metakaolin -lime-water systems. Cement and Concrete Research, 32,133-138.

Midgley H G \& Bhaskara Rao, P. (1978). Formation of Stratlingite, $2 \mathrm{CaO} \cdot \mathrm{SiO}_{2} \cdot \mathrm{Al}_{2} \mathrm{O}_{3} \cdot 8 \mathrm{H}_{2} \mathrm{O}$ in relation to the hydration of High Alumina Cement. Cement and Concrete Research, 8,169-172.

Mohamed Heikal, Mohamed Mahmoud Radwan \& Mohamed Saad Morsy. (2004). Influence of curing temperature on the Physico-mechanical, Characteristics of Calcium Aluminate Cement with air cooled Slag or water cooled Slag. Ceramics- Silikáty, 48(4), 185-196,

Mohamed Heikal. (2006). Effect of temperature on the Structure and Strength properties of cement pastes containing Fly ash alone or in combination with Limestone. Ceramics - Silikáty, 50(3), 167-177.

Mohamed S.Morsy \& Sayed S.Shebl. (2007). Effect of Silica Fume and Metakaoline Pozzolana on the Performanance of blended cement pastes Against Fire. Ceramics- Silikáty, 51(1), 40-44.

Ping Gu, Beaudoin, J.J. (1997). A Conduction Calorimetry Study of early hydration of Ordinary Portland Cement/High Alumina Cement Pastes. J. of Materials Science, 32, 3875-3881.

Sivakumar, G., Mohanraj, K.,Senthilmurugan, S., Nithya, R., and Barathan, S. (2008). The influence of chemical composition on flyash-cement Composite. Eco Chronicle, 3(1),37-42.

Shetty, M.S. (2004). Concrete Technology, 42.

Table 1. Percentage Chemical composition of Materials

\begin{tabular}{lllllllll}
\hline Materials & Oxides & \multicolumn{7}{l}{} \\
\hline & $\mathrm{CaO}$ & $\mathrm{Al}_{2} \mathrm{O}_{3}$ & $\mathrm{SiO}_{2}$ & $\mathrm{Fe}_{2} \mathrm{O}_{3}+\mathrm{FeO}$ & $\mathrm{MgO}$ & $\mathrm{Na}_{2} \mathrm{O}$ & $\mathrm{SO}_{3}$ & Others \\
$\mathrm{HAC}$ & 38.5 & 39 & 4.5 & 14 & 0.4 & 0.1 & 0.15 & 3.15 \\
$\mathrm{OPC}$ & 63.41 & 5.45 & 21.45 & 3.42 & 2.59 & 0.38 & 2.39 & 0.91 \\
$\mathrm{SF}$ & 0.45 & 1.17 & 93.14 & 3.13 & 0.98 & 0.30 & 0.10 & 0.73 \\
\hline
\end{tabular}


Table 2. Contents of the Ground Water

\begin{tabular}{ll}
\hline Content & Ground Water \\
\hline Total Dissolved Solids & 1401 \\
Total Hardness & 158 \\
Chlorine & 55 \\
Sodium & 120 \\
Magnesium & 12 \\
Calcium & 66 \\
Potassium & 15 \\
Sulphur & 7.1 \\
Fluoride & 0.08 \\
Electrical conductivity & 500 \\
$\mathrm{P}^{\mathrm{H}}$ & 7.8 \\
\hline
\end{tabular}

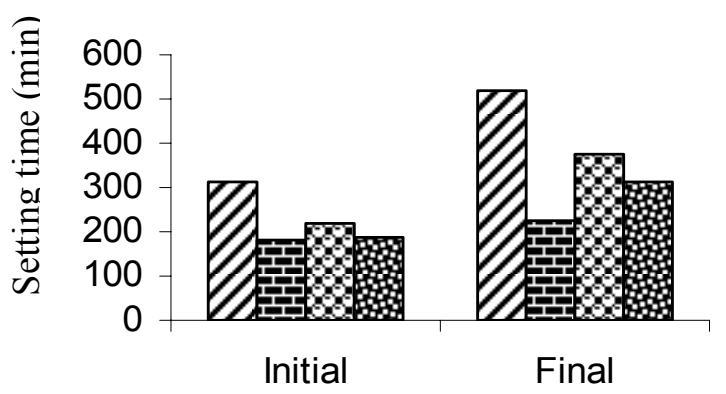
a HAC
I $90 \% \mathrm{HAC}+10 \% \mathrm{OPC}$
ㅁ $80 \% \mathrm{HAC}+10 \% \mathrm{OPC}+10 \% \mathrm{SF}$. $70 \% \mathrm{HAC}+10 \% \mathrm{OPC}+20 \% \mathrm{SF}$

Figure 1. Setting time of the admixtured cement paste

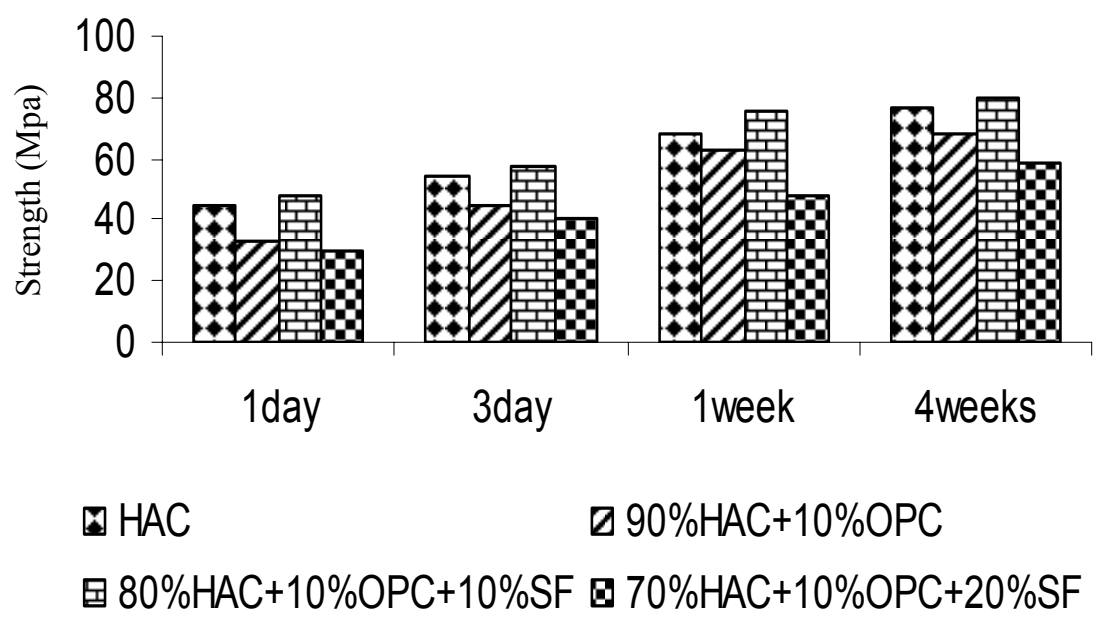

Figure 2. Compressive strength of admixtured cement paste 


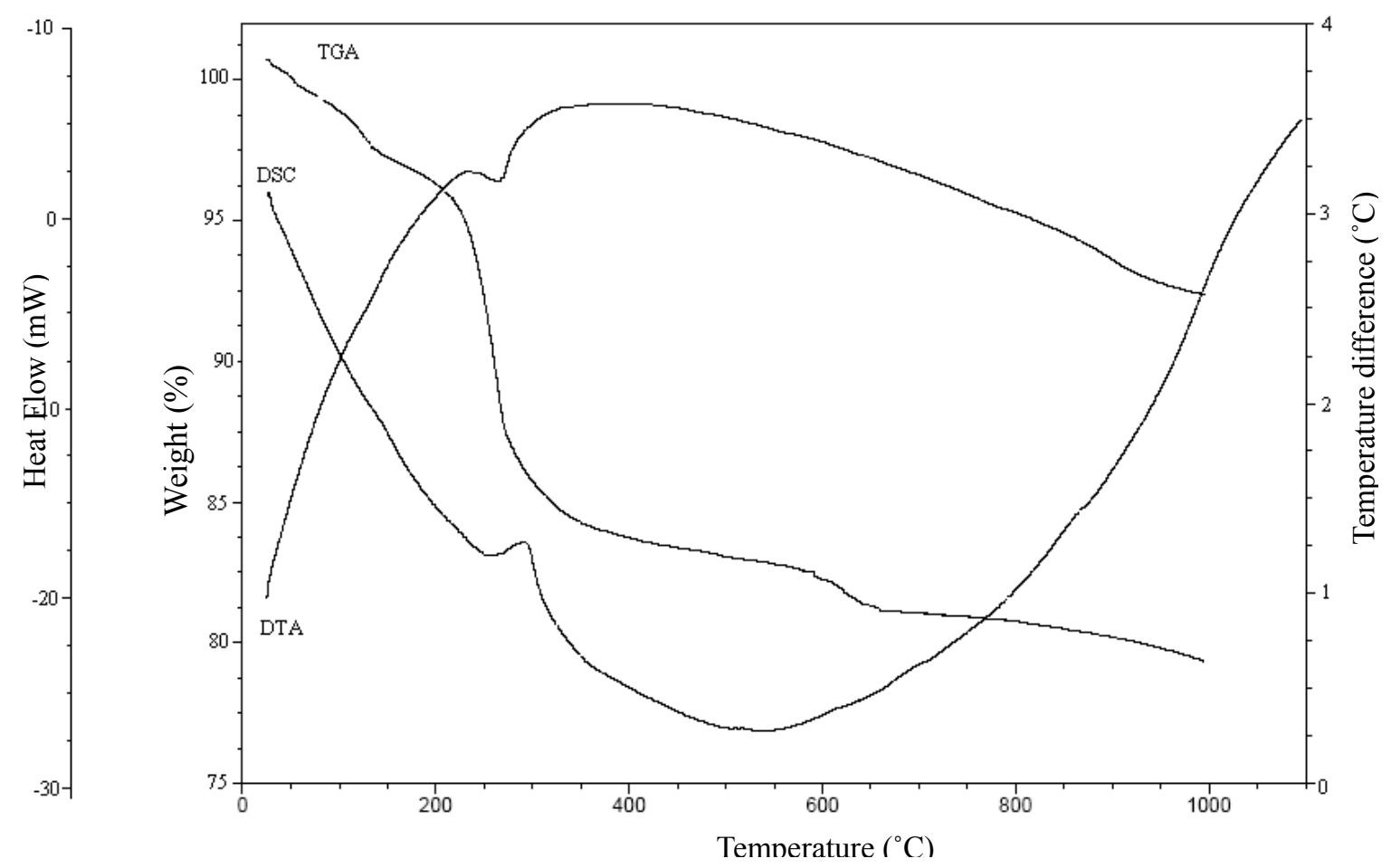

Figure 3. DTA/TG and DSC Spectrograms of Hydrated HAC

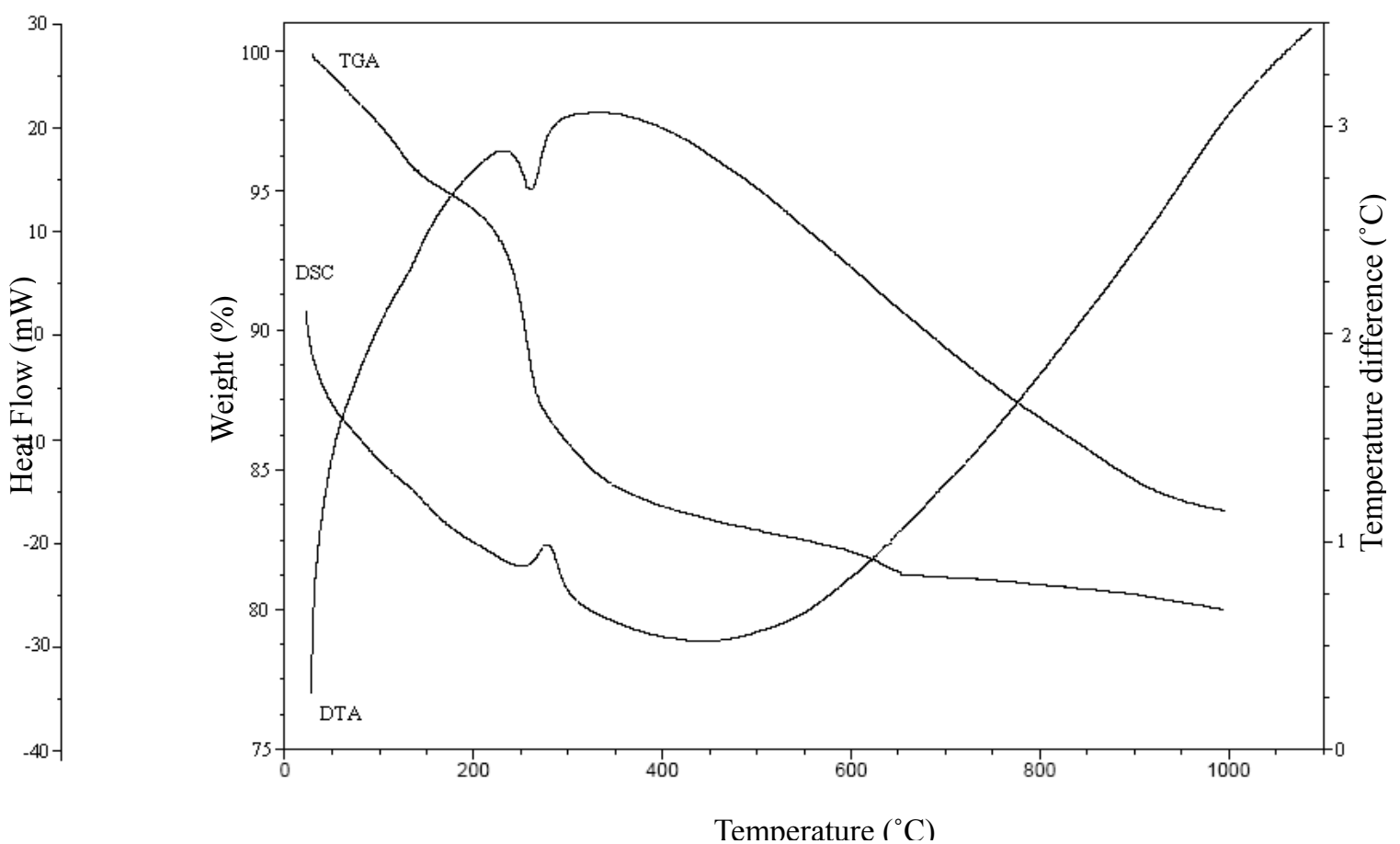

Figure 4. DTA/TG and DSC Spectrograms of $90 \% \mathrm{HAC}+10 \% \mathrm{OPC}$ 


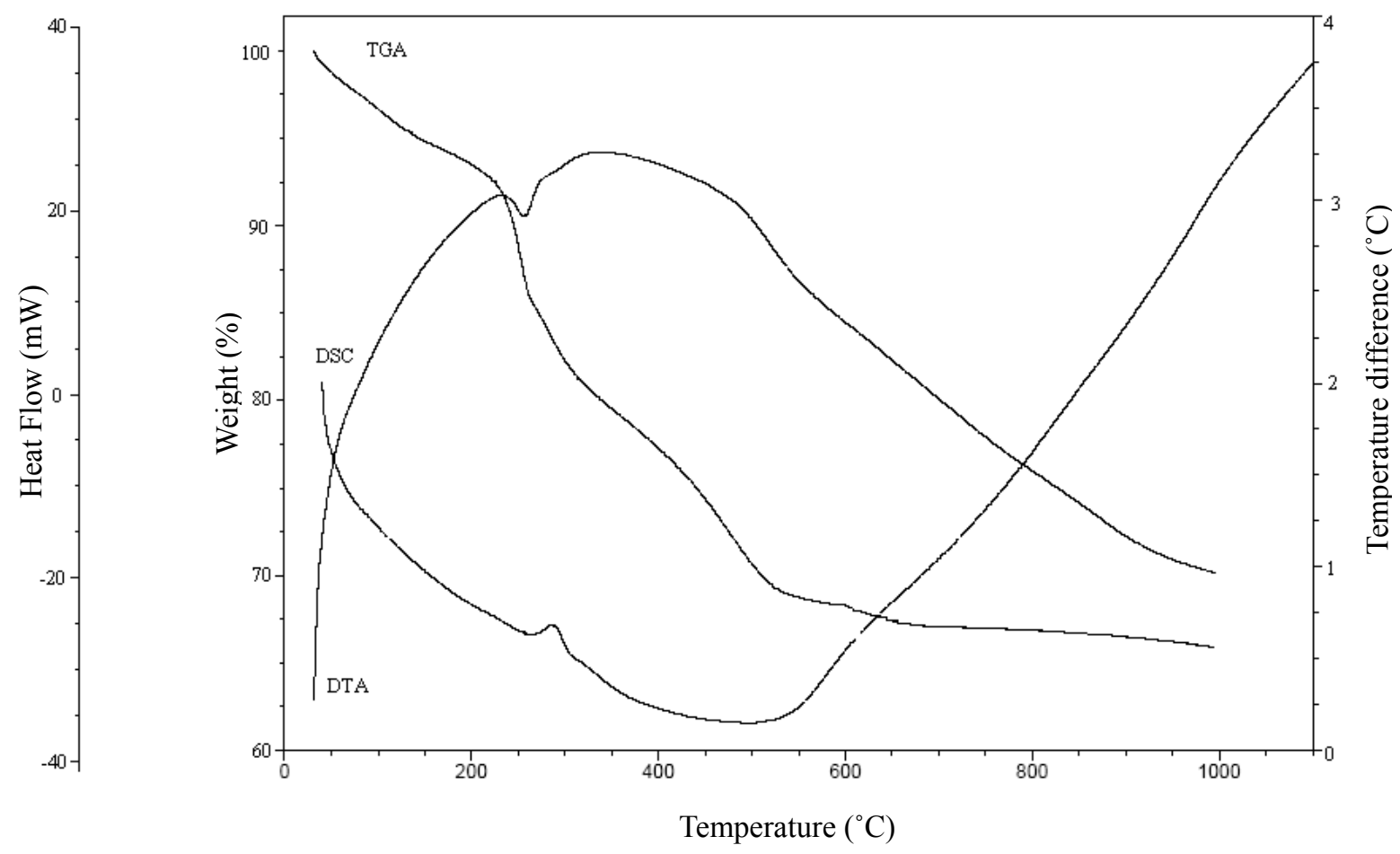

Figure 5. DTA/TG and DSC Spectrograms of $80 \% \mathrm{HAC}+10 \% \mathrm{OPC}+10 \% \mathrm{SF}$

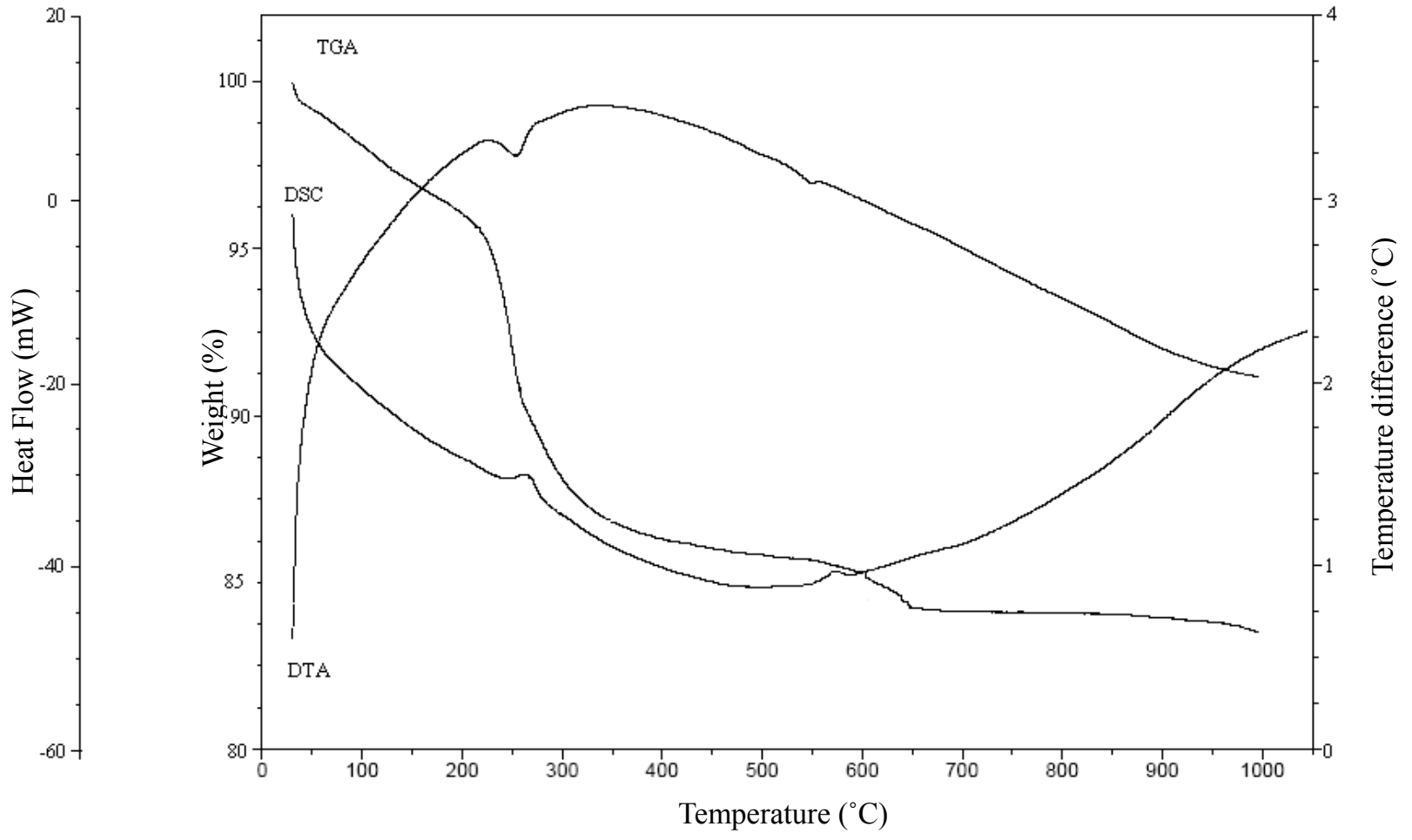

Figure 6. DTA/TG and DSC Spectrograms of $70 \% \mathrm{HAC}+10 \% \mathrm{OPC}+20 \% \mathrm{SF}$ 